\title{
A BASE NACIONAL COMUM CURRICULAR E A FORMAÇÃO DE PROFESSORES DE LÍNGUA INGLESA: DESAFIOS E POSSIBILIDADES
}

\author{
BASE NACIONAL COMÚN CURRICULAR Y LA FORMACIÓN DE PROFESORES DE \\ LENGUA INGLESA: DESAFÍOS Y POSIBILIDADES
}

\author{
BRAZIL'S NATIONAL COMMON CURRICULAR BASE (BNCC) AND THE TRAINING \\ OF ENGLISH LANGUAGE TEACHERS: CHALLENGES AND POSSIBILITIES
}

\author{
Caique Fernando da Silva FISTAROL ${ }^{1}$ \\ Adriana FISCHER ${ }^{2}$ \\ Rosana Clarice Coelho WENDERLICH ${ }^{3}$
}

\begin{abstract}
RESUMO: O objetivo do presente artigo é analisar a última versão da Base Nacional Comum Curricular - BNCC (BRASIL, 2017) quanto à formação de professores de língua inglesa na Educação Básica. São analisadas propostas presentes nesta versão da BNCC, à luz de enfoques teóricos como saberes docentes, teoria dialógica da linguagem, inglês como língua franca e práticas pedagógicas com tecnologias em língua inglesa. Os principais resultados apontam para práticas em língua inglesa articuladas com os diferentes usos, seja com apoio da oralidade, de leituras, de escritas, mediadas também por tecnologias, na direção da formação integral dos estudantes. Em consequência, é proposto aos professores que trabalhem essas práticas de forma articulada, para estabelecer interações com outras culturas e componentes curriculares, com contextos de uso efetivo da língua inglesa, na formação crítica dos estudantes da Educação Básica.
\end{abstract}

PALAVRAS-CHAVE: Língua inglesa. Formação de professores. Base Nacional Comum Curricular.

RESUMEN: El objetivo del presente artículo es analizar la última versión de Base Nacional Común Curricular - BNCC (BRASIL, 2017) en cuanto a la formación de profesores de lengua inglesa en la Educación Básica. Se analizan propuestas presentes en esta versión de la BNCC, a la luz de enfoques teóricos como saberes docentes, teoría dialógica del lenguaje, inglés como lengua franca y prácticas pedagógicas con tecnologías en lengua inglesa. Los principales resultados apuntan a prácticas en lengua inglesa articuladas con los diferentes usos, sea con apoyo de la oralidad, de lecturas, de escrituras, mediadas también por tecnologías, en la dirección de la formación integral de los estudiantes. En consecuencia, se propone a los

\footnotetext{
${ }^{1}$ Secretaria Municipal de Educação de Blumenau (SEMED), Blumenau, SC - Brasil. Coordenador Curricular de Línguas Estrangeiras do Ensino Fundamental. ORCID: <https://orcid.org/0000-0001-7650-7324>. E-mail: caiquefistarol@blumenau.sc.gov.br.

${ }^{2}$ Fundação Universidade Regional de Blumenau (FURB), Blumenau - Santa Catarina - Brasil. Vice coordenadora e Professora do Programa de Pós-Graduação em Educação (Mestrado e Doutorado). ORCID: <https://orcid.org/0000-0001-9787-2814>.E-mail: adrfischer@ furb.br.

3 Fundação Universidade Regional de Blumenau (FURB), Blumenau - Santa Catarina - Brasil. Mestranda em Educação na linha de Linguagens, Arte e Educação do Programa de Pós-Graduação e Educação da Universidade Regional de Blumenau (FURB). Bolsista de apoio técnico CNPQ. ORCID: <https://orcid.org/0000-0002-54045891>. E-mail: rwenderlich@ furb.br.
} 
profesores que trabajen esas prácticas de forma articulada, para establecer relaciones con otras culturas y componentes curriculares, con contextos de uso efectivo de la lengua inglesa, en la formación crítica de los estudiantes de Educación Básica.

PALABRAS CLAVE: Lengua inglesa. Formación de profesores. Base Nacional Común Curricular.

ABSTRACT: This article analyzes the latest version of Brazil's National Common Curricular Base (BNCC) (BRAZIL, 2017) regarding the training of English language teachers in Basic Education. The proposals presented on the BNCC version are analyzed in the light of theoretical approaches such as teacher knowledge, dialogical theory of language, English as a Lingua Franca and pedagogical practices with technologies in the English language. The results point to the English practices articulated with the different uses, with the support of orality, of the readings, of the writings, mediated by technologies, towards the integral formation of the students. Hence, it is proposed to teachers to work on these practices in an articulated way, in order to establish interactions together with cultures and curricular components, with contexts of effective use of the English language, in the critical formation of students of Basic Education.

KEYWORDS: English language. Training of English language teachers. Brazil's National Common Curricular Base.

\section{Primeiras considerações}

Cabe à União estabelecer, em colaboração com os Estados, o Distrito Federal e os Municípios, competências e diretrizes para a Educação Infantil, o Ensino Fundamental e o Ensino Médio, que nortearão os currículos e seus conteúdos mínimos, de modo a assegurar formação básica comum (BRASIL, LDB, 1996, artigo $9^{\circ}$, capítulo IV).

Essa referência [à BNCC] é o ponto ao qual se quer chegar em cada etapa da Educação básica, enquanto os currículos traçam o caminho até lá (BRASIL, MEC, 2017, p. 5).

A Lei de Diretrizes e Bases da Educação brasileira n ${ }^{\circ} 9.394$ (BRASIL, 1996), citada no primeiro excerto da epígrafe, nos aponta elementos que são retomados na Base Nacional Comum Curricular - BNCC (BRASIL, 2017) como o ideal de uma Educação Básica comum a todos os brasileiros, sem distinção de classe social, econômica, cultural e/ou ainda independentemente da localização geográfica, de aspectos étnico-raciais, religiosos, linguísticos, entre outros. Conforme assegura a Constituição brasileira (BRASIL, 1988), a todos deve ser garantido o direito à educação, sendo esta gratuita e de qualidade. Complementa o artigo 206, inciso I, a "igualdade de condições de acesso e permanência na escola" para todos 
os brasileiros (BRASIL, 1988). Neste sentido, a BNCC (BRASIL, 2017) vem reforçar esse direito a partir de um currículo comum e, apesar de já constar no artigo $9^{\circ}$, capítulo IV da LDB no 9.394 (BRASIL, 1996), é a primeira vez, que o Brasil tem uma base curricular comum, que passa a definir as aprendizagens essenciais a que os estudantes têm direito, pontualmente, no Ensino Fundamental no nível da Educação Básica. Entretanto, dependerá do currículo adotado pela escola, a forma de implementação.

Conforme o site do Ministério da Educação ${ }^{4}$, a BNCC “[...] é um documento de caráter normativo que define o conjunto orgânico e progressivo de aprendizagens essenciais que todos os alunos precisam desenvolver ao longo das etapas e modalidades da Educação Básica" (BRASIL, MEC, 2017, p. 7). Portanto, a BNCC (BRASIL, 2017) que vislumbra uma formação humana e integral do estudante da Educação Básica busca a partir das diferentes inserções sociais, culturais, linguísticas apresentadas por esses estudantes na escola, assegurar o direito que este tem de aprender e a desenvolver o exercício pleno da cidadania. Para tanto, este documento parte de um diálogo que fortaleça e una as políticas educacionais nas esferas federal, estadual e municipal e promova a qualidade da educação diante de um currículo comum a todos (BRASIL, 2017).

A partir desse processo, a formação continuada de professores torna-se fundamental, visto que novos procedimentos, práticas e saberes exigirão dos professores uma formação diferente daquela até então oferecida em cursos de licenciaturas, incluindo Pedagogia e Letras, nas universidades brasileiras, como revelam dados da pesquisa de Fistarol, Fischer e Bailer (2018). Cabe ressaltar, entretanto, que anteriormente à publicação da BNCC (BRASIL, 2017) outros programas e cursos de formação continuada já vinham sendo oferecidos aos professores da Educação Básica pelo governo federal em parceria com os estados e municípios brasileiros, a saber: o Programa Gestão da Aprendizagem Escolar - GESTAR I (2004) e GESTAR II (2006), Mobilização pela Qualidade da Educação - PRÓ-LETRAMENTO (2008), Pacto Nacional pela Alfabetização na Idade Certa - PNAIC (2012) direcionados aos professores que atuam no Ensino Fundamental, e o Pacto Nacional pelo Fortalecimento do Ensino Médio PNEM (2014), voltado para professores do Ensino Médio.

Com base nesta contextualização inicial, é objetivo deste artigo analisar a última versão da BNCC (BRASIL, 2017) quanto à formação de professores de língua inglesa na Educação Básica. A metodologia pauta-se em uma abordagem qualitativa, a qual se compõe por discursos e excertos que foram selecionados da BNCC (BRASIL, 2017). Enfoques teóricos que dão

${ }^{4}$ Disponível em: http://basenacionalcomum.mec.gov.br/. Acesso em: 04 mar. 2019. 
suporte às análises, neste trabalho, que recaem sobre saberes docentes, com apoio de Tardif (2002) e Nóvoa (1995, 2009, 2011); perspectiva dialógica da linguagem, baseada em Bakhtin (2003); a prática pedagógica em língua inglesa, que se quer diferenciada e crítica, com estudos de Leffa (2008); e a língua inglesa como fonte de transformação do pensamento, a partir de pesquisas de Ortega (2009) e Seidlhofer (2001).

Para atender ao objetivo deste artigo, portanto, este se organiza da seguinte forma, após esta introdução: um enfoque contextual em torno da "BNCC e a Educação Básica: competências gerais"; a terceira seção aborda "a formação de professores, os saberes docentes e o uso das tecnologias"; a quarta seção propõe discussões em torno do "lugar da língua inglesa na BNCC” e; por fim; seguem as considerações finais e as referências.

\section{A BNCC e a Educação Básica: competências gerais}

A Educação Básica tem sido foco de intensos debates, desde 2014, por ocorrência das primeiras elaborações da BNCC no Brasil. O ensino público, é principalmente, colocado em destaque quanto a princípios, concepções, proposições, entre tantos outros enfoques que emergem, gradativamente, na proposta da BNCC. Este documento

[...] teve o início de sua elaboração em 2014 e contou com intensa participação da sociedade. A primeira versão da BNCC, apresentada em 2015, recebeu 12 milhões de contribuições, em consulta pública, e deu origem à segunda versão, em maio de 2016. A partir daí o Conselho Nacional de Secretários de Educação (Consed) e a União Nacional dos Dirigentes Municipais de Educação (Undime), com apoio do MEC, promoveram seminários em todas as 27 unidades da federação, entre junho e agosto de 2016. Os seminários mobilizaram 9 mil professores, gestores e acadêmicos. A versão final, [submetida no dia 06/04/17] ao Conselho Nacional de Educação (CNE), valeu-se de toda essa discussão e passou pelo crivo de especialistas (BRASIL, 2017, s./p. $)^{5}$.

Assim, ao ser aprovada e homologada pelo Conselho Nacional de Educação - CNE, a BNCC para o Ensino Fundamental (BRASIL, 2017) passou a ser referência obrigatória na elaboração dos currículos de escolas brasileiras públicas e particulares, tendo como prazo de sua implementação até o ano de 2020 (BRASIL, 2017, s./p.) ${ }^{6}$. Esse dado indica que modificações curriculares das escolas públicas e privadas são obrigatórias, a partir da

${ }^{5}$ Disponível em: http://portal.mec.gov.br/component/content/article?id=47111. Acesso em: 04 mar. 2019.

${ }^{6}$ Disponível em: http://portal.mec.gov.br/component/content/article?id=47111. Acesso em: 04 mar. 2019.

RPGE- Revista on line de Política e Gestão Educacional, Araraquara, v. 23, n. 2, p. 341-355, maio/ago., 2019. E-ISSN:1519-9029. 
homologação do documento da BNCC pelo Ministério da Educação - MEC, o que prevê transformações no que se refere, principalmente, à concepção de escola.

Em relação aos conteúdos, há uma alteração, visto que deixam de orientar as ações educativas e passam a auxiliar os estudantes no processo de apropriação das competências e habilidades que contribuam para superação das dificuldades que podem surgir em suas vidas. A BNCC (BRASIL, 2017) estabelece que, durante a Educação Básica, os estudantes precisam desenvolver competências gerais - cognitivas e socioemocionais - incluindo o estímulo à curiosidade intelectual, o uso das tecnologias e a valorização da diversidade dos sujeitos. Quanto às competências gerais da BNCC (BRASIL, 2017, p. 8), o documento propõe que estas se inter-relacionem e desdobrem-se "no tratamento didático proposto para as três etapas da Educação Básica", a fim de auxiliar na construção de conhecimentos, no desenvolvimento de habilidades e na formação de atitudes e valores, conforme assevera também a LDB nº 9.394 (BRASIL, 1996) ${ }^{7}$.

Dentre as competências propostas, estão a valorização e o uso de conhecimentos construídos na e pela história, na e pela relação com o outro; a promoção da curiosidade intelectual a partir da pesquisa científica; o desenvolvimento do senso crítico, a partir das diversas manifestações culturais; o uso de diferentes linguagens verbal e verbo-visual nos processos de ensino e aprendizagem, com o intuito de que os sujeitos produzam sentidos com apoio no que aprenderam; o uso de recursos tecnológicos, considerando as diversas práticas sociais de leitura e escrita - as escolares e não escolares; a valorização e o respeito à diversidade de saberes, de vivências e de experiências sociais, culturais e históricas; a posição que se pode e deve assumir diante de diferente situações em diferentes esferas sociais (escola, família, trabalho), defendendo assim, seu ponto de vista, seus valores, suas crenças (BRASIL, 2017). ${ }^{8}$

A formulação das competências gerais ${ }^{9}$, mencionadas anteriormente, não prevê a ideia de que os professores precisam planejar uma aula específica sobre essas competências ou transformá-las em componente curricular, mas que consigam fazer os alunos articularem seus conhecimentos a outras habilidades relacionadas a diversas áreas do conhecimento.

Ao afirmar que devemos "exercitar a curiosidade intelectual e recorrer à abordagem própria das ciências, incluindo a investigação, a reflexão, a análise crítica, a imaginação e a

\footnotetext{
${ }^{7}$ Disponível em: http://portal.mec.gov.br/seesp/arquivos/pdf/lei9394_ldbn1.pdf. Acesso em: 26 mar. 2019.

${ }^{8}$ Disponível em: http://basenacionalcomum.mec.gov.br/wp-content/uploads/2018/02/bncc-20dez-site.pdf. Acesso em: 04 mar. 2019.

9 "Na BNCC, competência é definida como a mobilização de conhecimentos (conceitos e procedimentos), habilidades (práticas, cognitivas e socioemocionais), atitudes e valores para resolver demandas complexas da vida cotidiana, do pleno exercício da cidadania e do mundo do trabalho" (BRASIL, 2017, p. 8).
} 
criatividade, para investigar causas, elaborar e testar hipóteses, formular e resolver problemas e inventar soluções com base nos conhecimentos das diferentes áreas" (BRASIL, 2017, p. 09), observamos que há uma preocupação da BNCC quanto ao desenvolvimento socioemocional que, para ser efetivado, deve estar materializado no cotidiano escolar, permeando componentes curriculares e ações. Portanto, os desafios são postos, visto que este processo afeta não apenas os currículos, mas a prática educativa de ensino e aprendizagem, a gestão, a formação de professores e os processos de avaliação.

Como já apresentado, o principal objetivo do MEC, com a implementação da BNCC, é minimizar as distinções verificadas no país, resultado de aspectos referentes ao entorno social de cada escola. Além disso, pretende-se tornar a escola e a educação efetivas mediante ações de valorização do que é local e articulando-as com a esfera global. Sob esta ótica, requer de professores e estudantes uma relação com os saberes que vai além do que cada disciplina geralmente está acostumada: um trabalho interdisciplinar entre as áreas do conhecimento. Portanto, é importante que tanto o professor quanto o gestor educacional dialoguem sobre o desenvolvimento de competências na relação entre conhecimento do conceito e materialidade social a partir de formações continuadas em serviço, em reuniões pedagógicas, assim como busquem fazer essa mediação do conhecimento com o estudante na sala de aula, na e pela interação verbal (BAKHTIN, 2003).

Torna-se imprescindível que os envolvidos (professores, gestores) com a educação estudem a legislação vigente para que construam estratégias de atuação perante novas orientações visando a implementação da BNCC. São ações que consideramos relevantes para este processo de transição, no período de implementação das propostas da BNCC: criação de frentes de estudo, diálogo com pessoas que tiveram experiências bem-sucedidas, busca de ideias e realizações inspiradoras no exterior, investimento em formas inovadoras de aula, comunicação efetiva e instigante com os estudantes, mobilização da curiosidade intelectual, trabalho com conceitos científicos, leituras e estudos entre pares ou grupos.

Por meio de ações como essas, citadas no parágrafo anterior, considerando os diferentes contextos escolares, compreendendo quais são as competências indicadas na BNCC para a Educação básica, abordamos, na seção seguinte, de que maneira a implementação da BNCC se articula à formação de professores de línguas, quais são os saberes docentes que são mais enfatizados e como o uso das tecnologias se efetiva nessa perspectiva. 


\section{A formação de professores, os saberes docentes e o uso das tecnologias}

[...] quanto mais um saber é desenvolvido, formalizado, sistematizado, como acontece com as ciências e os saberes contemporâneos, mais se revela longo e complexo o processo de aprendizagem que exige, por sua vez, uma formalização e uma sistematização adequada (TARDIF; LESSARD; LAHAYE, 1991, p. 219).

A legitimação dos saberes docentes e do desenvolvimento profissional estão permeadas pelas experiências, vivências, saberes científicos e pedagógicos que constituem o docente. Neste percurso há que se ressaltar "os desafios impostos pela multiplicação das tecnologias e da cultura digital dos últimos tempos que têm os jovens como seus maiores protagonistas, trazendo à baila desafios enfrentados pelos professores para apropriar-se destes recursos" (BRASIL, 2017, p. 61).

Partindo desta asserção em torno dos desafios na formação docente, a presente seção tem como aspecto fundamental tratar da formação docente a partir das orientações previstas na BNCC, relacionando-a aos saberes docentes, especialmente, ao uso de recursos tecnológicos e processos de ensinar e aprender. Partimos do pressuposto de que a formação de professores deve valorizar os saberes da experiência (TARDIF, 2002) pois, por meio dela, o sujeito tem a possibilidade de refletir acerca da sua prática docente. A interdisciplinaridade contribuirá de maneira efetiva para a formação da identidade profissional do professor, como se manifesta nas proposições da BNCC. Jorge (2002) aponta que é preciso haver uma articulação entre as bases teóricas que fundamentam o ensino da língua e o desenvolvimento de habilidades que permitam a análise e a escolha de contextos de intervenção para o ensino. Nesse sentido, Nóvoa (1995, p. 25) defende:

a formação não se constrói por acumulação (de cursos, de conhecimentos ou de técnicas), mas sim através de um trabalho de reflexividade crítica sobre as práticas e de (re)construção permanente de uma identidade pessoal. Por isso é tão importante investir na pessoa e dar um estatuto ao saber da experiência.

Os dizeres de Nóvoa reforçam o quanto a formação de professores é um tema complexo e necessário de ser desenvolvido dentro das instituições e em grupos de estudo e pesquisa. Este autor sinaliza a importância da ampliação do conhecimento cultural e científico do professor, ainda que alguns desafios dificultem o desenvolvimento desse profissional e a construção de sua identidade de forma individual e coletiva.

Sobre a relação com os saberes, Tardif (2002) caracteriza o professor como 
pedagogia, de desenvolver um saber prático baseado em sua experiência cotidiana com os alunos (TARDIF, 2002, p. 39).

Ao se reportar à língua inglesa, Leffa (2008) defende que ensinar uma língua estrangeira se torna uma ação política, em que o texto é um produto de forças ideológicas, sociais e políticas, com valores revolucionários, um local de luta, negociação e mudança. Tal abordagem procura construir propostas pedagógicas diferenciadas para que o estudante se construa como um cidadão crítico. A formação de professores, nesse sentido, deve privilegiar a realidade social em que está inserido, contextualizar para ensinar de modo significativo, construir elementos que auxiliem e orientem o saber fazer dos estudantes para resolver problemas cotidianos, como preconiza a BNCC, visando ao estímulo da criatividade para a resolução de problemas, ao trabalho coletivo e cooperativo, de maneira ética e ligada à cidadania.

Dentro desse contexto, há espaço para aquilo que já foi construído, porém a combinação de saberes e experiências, com o intuito de modernizar a educação nacional gradualmente dos níveis de ensino, objetiva novas possibilidades para a Educação Básica brasileira. Entre as competências gerais da BNCC, como indicamos na seção anterior, duas enfatizam de modo mais direto a inovação e a tecnologia: a de número 4, que estipula o uso de diferentes linguagens, inclusive a digital, para expressar e partilhar informações, e a de número 5, que determina a utilização e criação de tecnologias digitais de forma crítica, reflexiva e ética. Para ser um espaço de conhecimento e aprendizagem, é preciso que os sujeitos interajam na e pela cultura do uso tecnológico, como campo de luta, poder, diferença e significação na construção de saberes e conhecimentos (SANTOS; OKADA, 2003).

As diretrizes da BNCC auxiliam reconhecer que o uso de recursos tecnológicos pode auxiliar no desenvolvimento de habilidades cognitivas e socioemocionais dos estudantes. Por esse motivo, também há o desafio para a formação de professores, de contemplar o uso dessas tecnologias, para que haja a possibilidade de alinhar a prática docente às expectativas dos estudantes nascidos na era digital. Sabemos que existem cidades brasileiras em que o acesso a tais tecnologias é nulo ou limitado. Consequentemente, precisamos considerar as diferentes realidades nas quais esses sujeitos se inserem, vivem e sobrevivem. Ressaltamos que as tecnologias são entendidas como criações humanas e, por isso, reconhecidas como importantes aliadas para potencializar o desenvolvimento de competências e habilidades no processo educativo (TURNES, 2014).

Outro elemento importante, e que está ligado às tecnologias na listagem de competências gerais da BNCC, são os processos linguísticos. Sob a ótica bakhtiniana 
a língua materna - sua composição vocabular e sua estrutura gramatical - não chega ao nosso conhecimento a partir do dicionário e da gramática, mas de enunciações concretas; [...] as formas da língua e as formas típicas dos enunciados $[. .$.$] chegam à nossa experiência e à nossa consciência em conjunto$ e estreitamente vinculadas (BAKHTIN, 2003, p. 283).

Portanto, faz-se necessário valorizar as experiências dos estudantes para que, neste caso, competências linguísticas sejam desenvolvidas, auxiliando no processo de construção de uma sociedade mais solidária com o compartilhamento de informações, vivências e ideias nos seus diferentes contextos sociais. Nesse sentido, com apoio na perspectiva dialógica da linguagem, do grupo de Bakhtin (2003), o sujeito é agente ativo do contexto em que participa, na relação com o mundo social. Com isso, ele tem a possibilidade de transformar o seu meio e a si mesmo, em uma relação dialógica com os outros e com os textos com os quais interage constantemente.

Para finalizar esta seção, compreendemos que a BNCC poderá auxiliar na melhoria da qualidade da Educação Básica do país, pois contribuirá para promover a equidade educacional por meio de competências gerais que estão relacionadas à realidade social de cada contexto. Partindo desse pressuposto, na próxima seção, abordamos as especificidades da BNCC propostas para a língua inglesa.

\section{O lugar da língua inglesa na BNCC}

Consideramos que a aprendizagem da língua inglesa possibilita a criação de novas formas de engajamento e participação dos estudantes em um mundo social cada vez mais globalizado e plural, como afirma Paiva (2014), ao defender que o ensino em sala de aula deva ser um espaço de socialização de culturas diferentes, problematizadas e ressignificadas dentro de diferentes perspectivas da língua como ferramenta comunicativa. Com isso, o estudo da língua inglesa pode possibilitar a todos o acesso a e a interação com saberes linguísticos diversos ou heterogêneos, contribuindo para o exercício da cidadania. Além disso, em perspectiva, possibilita a interação e mobilidade, abrindo novos percursos de construção de conhecimentos. Ortega (2009, p. 219, tradução nossa) defende que a língua é uma "ferramenta usada para criar pensamentos, mas ela também transforma o pensamento e é fonte de aprendizagem" ${ }^{\prime 10}$. Nesse contexto, é que surge o conceito de língua franca, que concebe o inglês como uma língua de contato entre pessoas que não compartilham de uma mesma língua mãe nem de uma mesma cultura; que está, segundo Seidlhofer (2001), fortemente ligada ao

${ }^{10}$ No original: "[...] tool used to create thought, but it also transforms thought and is a source of learning". 
desenvolvimento econômico e tecnológico; que também está associada a diferentes intenções de uso, conferindo-lhe status de franca, sem propriedade global.

Diante desses aspectos, a língua inglesa foi definida como idioma obrigatório a ser ensinado no Ensino Fundamental II, do $6^{\circ}$ ao $9^{\circ}$ ano, de todas as escolas brasileiras pela BNCC, em que há prescrição de algumas habilidades nesta língua, que os estudantes desse nível precisam dominar. Estas habilidades são divididas em cinco eixos: oralidade, leitura, escrita, conhecimentos linguísticos e gramaticais, e dimensão intercultural. Ainda, está prevista uma forma de trabalho integrada e que auxilia na ampliação de repertório cultural e linguístico dos estudantes.

É imprescindível dizer que esses eixos, embora tratados de forma separada na explicitação da BNCC, estão intrinsecamente ligados nas práticas sociais de usos da língua inglesa e devem ser assim trabalhados nas situações de aprendizagem propostas no contexto escolar. Em outras palavras, é a língua em uso, sempre híbrida, polifônica e multimodal que leva ao estudo de suas características específicas, não devendo ser nenhum dos eixos, sobretudo o de conhecimentos linguísticos, tratado como pré-requisito para esse uso (BRASIL, 2017, p. 243).

Ao ressaltar que a língua inglesa seja abordada a partir das práticas sociais trazidas para o contexto escolar, compreendemos que para o ensino da língua inglesa, devemos partir das experiências e das vivências que os estudantes trazem para a escola, do uso que ele faz no seu cotidiano da língua inglesa a partir da leitura de manuais de instrução de jogos; de instalação de programas; ao ouvir uma música; ou ainda, ao trocar mensagens pelas redes sociais com estrangeiros que falam o idioma inglês. Além disso, depreende-se que o estudante pode apresentar diferentes dialetos da língua inglesa dos diferentes usados na norma culta da língua inglesa, o que implica pensar a língua como heterogênea, assim como os sujeitos que a usam também o são. Para tanto, elencamos quais são as competências específicas de língua inglesa para o Ensino Fundamental II, previstas na BNCC (BRASIL, 2017, p. 244), levando-se em consideração aquilo que o estudante já sabe sobre a língua inglesa, o conhecimento linguístico que a escola, na mediação do professor e do estudante, irá colocar em ação, ampliando assim, o repertório linguístico desse estudante:

1. Identificar o lugar de si e o do outro em um mundo plurilíngue e multicultural, refletindo, criticamente, sobre como a aprendizagem da língua inglesa contribui para a inserção dos sujeitos no mundo globalizado, inclusive no que concerne ao mundo do trabalho.

2. Comunicar-se na língua inglesa, por meio do uso variado de linguagens em mídias impressas ou digitais, reconhecendo-a como ferramenta de acesso ao conhecimento, de ampliação das perspectivas e de possibilidades para a 
compreensão dos valores e interesses de outras culturas e para o exercício do protagonismo social.

3. Identificar similaridades e diferenças entre a língua inglesa e a língua materna/outras línguas, articulando-as a aspectos sociais, culturais e identitários, em uma relação intrínseca entre língua, cultura e identidade.

4. Elaborar repertórios linguístico-discursivos da língua inglesa, usados em diferentes países e por grupos sociais distintos dentro de um mesmo país, de modo a reconhecer a diversidade linguística como direito e valorizar os usos heterogêneos, híbridos e multimodais emergentes nas sociedades contemporâneas.

5. Utilizar novas tecnologias, com novas linguagens e modos de interação, para pesquisar, selecionar, compartilhar, posicionar-se e produzir sentidos em práticas de letramento na língua inglesa, de forma ética, crítica e responsável. 6. Conhecer diferentes patrimônios culturais, materiais e imateriais, difundidos na língua inglesa, com vistas ao exercício da fruição e da ampliação de perspectivas no contato com diferentes manifestações artísticoculturais.

As competências específicas para a língua inglesa apontam vários elementos que precisam ser considerados pelos professores. Os professores exercerão papel fundamental na implementação dessas propostas da BNCC e necessitam ter clareza do contexto do estudante, para definir como o currículo será materializado. Conforme Fistarol (2018, p. 104), “a função social da profissão docente [...] aponta para a importância da atuação do professor para formar cidadãos críticos e para despertar conhecimentos e interesses nos estudantes”. Além disso, o professor terá autonomia de selecionar quais serão os recursos pedagógicos a serem utilizados com os diferentes perfis e níveis de conhecimento do idioma pelos estudantes.

Para finalizar, interpretamos que as competências de língua inglesa previstas na BNCC indicam que a articulação entre os diferentes usos da língua é imprescindível para o desenvolvimento de habilidades e formação integral dos estudantes. Por conseguinte, faz-se necessário que os professores trabalhem de forma articulada para que essas competências sejam oportunizadas e façam parte do cotidiano do estudante.

\section{Dos dados a encaminhamentos possíveis - palavras finais}

Neste artigo visamos analisar o que a última versão da BNCC (BRASIL, 2017), homologada pelo CNE, propõe para a formação de professores, com particularidades voltadas à língua inglesa, bem como desafios e possibilidades para sua implementação na Educação básica.

Reiteramos que a BNCC (BRASIL, 2017) tem como intuito possibilitar que estudantes de localidades diferentes acessem conhecimentos balizadores da educação para todos. Portanto, foram definidas aprendizagens essenciais a que os estudantes tenham direito na Educação 
Básica, ainda, à escola, especialmente ao professor compete o compromisso político que o reveste, pela materialização do desenvolvimento das competências previstas para cada nível de ensino. Essa afirmação não significa que o professor seja o único responsável pela implementação das propostas indicadas na BNCC (BRASIL, 2017), mas é um dos autores, que se quer engajado e comprometido tanto com particularidades dos contextos escolares de atuação, como também com as orientações nacionais para a educação.

Para que esse processo se efetive, o investimento em formação de professores é essencial, pois faz-se necessário que os professores conheçam as orientações previstas pela BNCC (BRASIL, 2017), para traçar estratégias de implementação em suas escolas. Além disso, é indispensável a partilha de saberes, conhecimentos e experiência nesse processo de formação.

Como apontamos anteriormente, a efetivação da BNCC (BRASIL, 2017) requer um trabalho interdisciplinar, que ultrapasse propostas previstas na organização dos componentes curriculares. Portanto, ao professor cabe compreender que o desenvolvimento de competências requer elações entre conhecimentos em torno do conceito de aprendizagem de língua inglesa, proposta na BNCC (BRASIL, 2017) e demais documentos norteadores da Educação e do contexto social dos estudantes.

Além disso, com as análises, identificamos que, entre as competências gerais da BNCC (BRASIL, 2017), pelo menos duas delas tratam da temática da inovação e da tecnologia, o que sugere que a formação de professores precisa abordar temáticas correlatas ao uso das tecnologias em âmbito escolar, como temos acompanhado em diversas pesquisas científicas (GONÇALVES, 2018; MENDES, 2017; LEFFA; DUARTE; ALDA, 2016; MIRANDA, 2016; KOMESU; GALLI, 2016) para o desenvolvimento de competências e habilidades por meio da sua utilização e criação de forma crítica, reflexiva e ética.

A depender do modo com que os professores desenvolvem percepção acerca de como estudantes interagem com as diferentes tecnologias no processo educativo, elas poderão se tornar um desafio ou uma possibilidade. Todavia, consideramos, necessária a utilização desses instrumentos tecnológicos no sentido de contemplar as expectativas geracionais dos estudantes que convivem socialmente com esses instrumentos (celular, tablet, computador, entre outros), assim como, ao considerar a língua inglesa como língua franca, oportunizar interações com outras culturas, com contextos de uso efetivo desta língua, na formação dos estudantes de Educação Básica. Por outro lado, não há como negar que há o desafio, ainda, de acesso dos estudantes e das próprias escolas às tecnologias.

A língua inglesa, prevista na BNCC (BRASIL, 2017), como idioma obrigatório a ser ensinado no Ensino Fundamental II, pode, também, ser considerado um elemento de demanda 
social, visto que o uso desta língua permite interação e mobilidade em um mundo social globalizado, no qual as fronteiras são, cada vez mais, tênues e ampliadas. Com isso, o estudo da língua inglesa contribui para o exercício da cidadania na medida em que amplia o repertório cultural e linguístico dos estudantes. Na BNCC (BRASIL, 2017), como já mencionado, é proposto que os estudantes ampliem esse repertório, partindo, também, de habilidades em torno de práticas de oralidade, de leitura, de escrita, de conhecimentos linguísticos e gramaticais, e da dimensão intercultural. Em consequência, requerem a articulação e reconhecimento da importância desses eixos pelos professores, os quais são agentes de transformação social.

Constatamos que a BNCC (BRASIL, 2017) enfatizou a importância da formação de sujeitos que consigam apreender na relação com suas experiências e realidades sociais, tenham capacidade de resolver conflitos, sejam criativos para se reinventar diante de crises e consigam superá-las e, sobretudo, busquem construir uma sociedade mais solidária.

Reforçamos que a BNCC (BRASIL, 2017) visa uma educação baseada nos princípios de equidade e justiça social. Para que esta proposta se torne efetiva, é imprescindível que a sua forma de implementação considere esses princípios, possibilitando a todos os cidadãos o acesso aos conhecimentos indicados pela BNCC (BRASIL, 2017).

AGRADECIMENTOS: Agradecemos à Secretaria Municipal de Educação de Blumenau, Senhora Patrícia Lueders, à Diretora de Educação Básica, Senhora Maria Luiza Oliveira e Diretora de Educação Infantil, Senhora Angela Maria Simão Hoemke pelos movimentos de formação de professores e desenvolvimento profissional docente da Rede Municipal de Blumenau.

\section{REFERÊNCIAS}

BAKHTIN, M. Estética da criação verbal. 4. ed. São Paulo: Martins Fontes, 2003.

BRASIL. Constituição da República Federativa do Brasil de 1988. [recurso eletrônico]. Brasília: Supremo Tribunal Federal, Secretaria de Documentação, 2018. Disponível em: http://www.stf.jus.br/arquivo/cms/legislacaoconstituicao/anexo/cf.pdf. Acesso em: 17 mar. 2019.

BRASIL. LEI $\mathbf{N}^{\circ} \mathbf{9 . 3 9 4}$ de 20 de dezembro de 1996. Disponível em: http://portal.mec.gov.br/seesp/arquivos/pdf/lei9394_ldbn1.pdf. Acesso em: 25 jul. 2018.

BRASIL. Programa Gestão da Aprendizagem Escolar - GESTAR I (2004) e II (2006). Disponível em: http://portal.mec.gov.br/index.php?option=com_docman\&view=download\&alias=446- 
apresentacao-geral-gestar-2-2009\&category_slug=documentos-pdf\&Itemid=30192. Acesso em: 07 jul. 2016.

BRASIL. Pró-Letramento: Programa de Formação Continuada de Professores dos Anos/Séries Iniciais do Ensino Fundamental: alfabetização e linguagem. - ed. rev. e ampl. incluindo SAEB/Prova Brasil matriz de referência/ Secretaria de Educação Básica - Brasília: Ministério da Educação, Secretaria de Educação Básica, 2008.

BRASIL. Pacto Nacional pela Alfabetização na Idade Certa - PNAIC. 2012. Disponível em: http://pacto.mec.gov.br/o-pacto. Acesso em: 07 jul. 2016.

BRASIL. Pacto Nacional pelo Fortalecimento do Ensino Médio - PNEM. 2014. Disponível em:

http://pactoensinomedio.mec.gov.br/index.php?option=com_content\&view=article\&id=22.

Acesso em: 07 abr. 2019.

BRASIL. Base Nacional Comum Curricular. Ministério da Educação (MEC), Brasília, 2017. Disponível

http://basenacionalcomum.mec.gov.br/documento/BNCCAPRESENTACAO.pdf. Acesso em: 04 mar. 2019.

FISTAROL, C. F. da S. Letramentos acadêmicos no curso de letras: práticas em inglês na voz de licenciandas. 2018. Dissertação (Mestrado em Educação) - Universidade Regional de Blumenau, Blumenau, 2018.

FISTAROL, C. F. S., FISCHER, A., BAILER, C. O processo de estágio na formação docente de professores de língua inglesa: um olhar de licenciandas de um curso de Letras. Revista iberoamericana de estudos em educação, v. 13, p. 623-637, 2018. Disponível em: https://periodicos.fclar.unesp.br/iberoamericana/article/view/11333/7361. Acesso em: 23 fev.2019.

GONÇALVES, K. Práticas de letramentos acadêmicos com tecnologias digitais: tensões, sentidos e expectativas de professores formadores em um LIFE. Blumenau, 2018. Dissertação (Mestrado em Educação), Universidade Regional de Blumenau, Blumenau, 2018.

JORGE, M. L. O ensino de inglês em turmas grandes. Ensino de língua estrangeira. APLIEMGE Newsletter. V. 7, n. 4. Dezembro, 2002.

KOMESU, F. C.; GALLI, F. C. S. Práticas de Leitura e escrita em contexto digital: autoria e(m) novos mídiuns. Revista da ABRALIN, v.15, n.2, p. 165-185, jul./dez. 2016. Disponível em: revistas.ufpr.br/abralin/article/download/47889/28824. Acesso em: 03 ago. 2016.

LEFFA, V. J. (Org.). O professor de línguas estrangeiras: construindo a profissão. 2. ed., Pelotas: EDUCAT, 2008.

LEFFA, V. J.; DUARTE, G. B.; ALDA, L. S. A sala de aula invertida: o que é e como se faz. In: JORDÃO, C. M. (Org.). A linguística aplicada no Brasil: rumos e passagens. Campinas: Pontes Editores, p. 365-386, 2016. 
MENDES, M.A. Letramentos acadêmicos na educação profissional e tecnológica: práticas de docentes com tecnologias digitais. 2017. Dissertação (Mestrado). Universidade Regional de Blumenau. Blumenau, SC.

MIRANDA, F. D. S. S. Letramentos (en)formados por relações dialógicas na universidade: (res)significações e refrações com tecnologias digitais. 2016. Tese (Doutorado) -. Universidade Estadual de Campinas, Instituto de Estudos da Linguagem. Campinas, 2016.

NÓVOA, A. (Coord.). Os professores e a sua formação. 2. ed. Lisboa: Dom Quixote, 1995.

NÓVOA, A. Professores: Imagens do futuro presente. Lisboa: Educa, 2009.

NÓVOA, A. Docência universitária e contemporaneidade. In: VII CONGRESSO INTERNACIONAL DE EDUCAÇÃO, Profissão docente: há futuro para esse ofício? Porto Alegre. Conferência de abertura. 2011.

ORTEGA, L. Understanding second language acquisition. London: Hodder Arnold, 2009.

PAIVA, V. L. M. de O. Aquisição de segunda língua. São Paulo: Parábola Editorial, 2014.

SANTOS, E. O. DOS; OKADA, A. L. P. A construção de ambientes virtuais de aprendizagem: por autorias plurais e gratuitas no ciberespaço. In: ANPED, GT: Educação e Comunicação. n. 16, Poços de Caldas, 2003. Anais... Disponível em: http://26reuniao.anped.org.br/trabalhos/edmeaoliveiradossantos.pdf. Acesso em: 10 jan. 2019.

SEIDLHOFER, B. Closing a conceptual gap: the case for a description of English as a lingua franca. International Journal of Applied Linguistics, Oslo, v. 11, n. 2, p. 133-158, 2001.

TARDIF, M. Saberes docentes e formação profissional. Petrópolis. RJ: Vozes, 2002.

TARDIF, M.; LESSARD, C.; LAHAYE, L. Os professores face ao saber: Esboço de uma problemática do saber docente. Teoria \& Educação. n. 4, Porto Alegre, p. 215-233, 1991.

TURNES, L. Pesquisa e pós-graduação: um estudo de caso sobre os usos das tecnologias por parte de doutorandos do PPGE/UFSC. Dissertação (Mestrado em Educação) Universidade Federal de Santa Catarina, Florianópolis, 2014. Disponível em: https://repositorio.ufsc.br/handle/123456789/129196. Acesso em: 13 jan.2019.

\section{Como referenciar este artigo}

FISTAROL, Caique Fernando da Silva; FISCHER, Adriana; WENDERLICH, Rosana Clarice Coelho. A Base Nacional Comum Curricular e a formação de professores de língua inglesa: desafios e possibilidades. Revista on line de Política e Gestão Educacional, Araraquara, v. 23, n. 2, p. 341-355, maio/ago., 2019. E-ISSN:1519-9029. DOI: 10.22633/rpge.v23i2.12453

Data de Submissão: 17/01/2019

Revisões Requeridas: 18/02/2019

Aceite em: 17/03/2019

Publicado em: 06/05/2019 